\title{
A Proposal for Continuous Assessment at Low Cost
}

\author{
David López, José R. Herrero, Alex Pajuelo, Alejandro Duran \\ Computer Architecture Department, Technical University of Catalonia, \\ UPC - Campus Nord Mòdul C6. C/ Jordi Girona 1-3. 08034 Barcelona, Spain \\ \{david, josepr, mpajuelo, aduran\}@ac.upc.edu
}

\begin{abstract}
Continuous assessment in higher education can have among its goals: (1) help students to organize their study throughout the course; (2) provide useful feedback to the students; (3) provide teachers with information on the students' progress and needs; and (4) have a final mark which does not depend uniquely on the result of a final examination. However, implementing continuous assessment usually results in additional effort for both the teacher and the student. As a consequence, there can be a lack of motivation for the teacher to implement this method and for the student to follow it. We present the methodology that we use in a course on Operating Systems at the Barcelona School of Informatics. We describe how the different parts of the methodology work to achieve the goals stated. We also evaluate the cost of applying our methodology, both for teachers and students, compared with other assessment methodologies. We have gathered data from different sources through five terms (students grades, students opinions, information about other courses) to evaluate our proposal. This evaluation backs our claim that our methodology achieves all the proposed goals.
\end{abstract}

Index Terms - Continuous assessment, Feedback, Learn how to learn, Low cost assessment.

\section{INTRODUCTION}

The Operating Systems (OS) course offered at the Barcelona School of Informatics, is in the core curriculum of the computer science engineering degree (i.e. it is mandatory to pass the course in order to obtain the degree).

Our students take this course in the fourth term, and it is the first one related to operating systems. It is preparatory for other courses in the curriculum: "Operating Systems Project" and "Operating Systems Administration". It is a basic course the difficulty of which lies in the amount of knowledge instead of in the difficulty of the knowledge itself.

Due to this great amount of knowledge and the strong interrelation between the ideas being presented, it is highly recommendable to study on a day-by-day basis. However, for years we observed that students studied mainly towards the examinations. This behavior provoked that master lectures and laboratories were not as useful as we wanted: students missed basic concepts and the experience of having previous exercises solved.

In 2003, our school partially adapted its curriculum to the new directives of the European Higher Education Area
(EHEA)[1]. We took the opportunity to change the assessment methodology. Our objectives were:

- To have the students do their homework on a day-by-day basis instead of concentrating their efforts on the days prior to the midterm and final examinations.

- To offer feedback promptly, separating the formative assessment from the summative one [2].

- To achieve our goals without increasing the workload, neither for the students nor the teachers.

In our proposal we change the assessment method for both the theoretical and practical (laboratory) parts of the course. For the theoretical part, students who pass the continuous evaluation can pass the course without taking the final examination. As for the laboratory, the evaluation is oriented to the exchange of information between the student and the teacher. We will show that these goals have been accomplished at a reasonable cost.

This article is organized as follows: first we present the context of our course and related work. Then we present the evaluation method, analyzing the cost of the proposal for teachers and students. Finally, we comment upon the results obtained from the five terms in which this course has been taught and present our conclusions.

\section{ENVIRONMENT}

Let us highlight some facts about the Spanish higher education environment in order to ease the understanding of the proposals introduced in this paper.

In our country, marks range between 0 (minimum) and 10 (maximum). The pass mark is 5. There are mandatory and optional courses, with a rigid ordering of related courses. For instance, it is not possible to enroll for "OS Project" before passing "OS". There are two terms per year (spring and fall). Each of them has 13 effective weeks spread over 15 calendar weeks. There is an additonal examination period of three weeks.

In our new curriculum, there are two different kinds of courses: "project" courses and "classical" ones. Project courses are based in the development of a mid-size project, with no master lectures, but with a tutor and one-to-one tutorial interviews. Due to the enormous amount of work of this kind of courses, students are encouraged to enroll for only one project course per term.

Classical courses have contact time sessions every week, with master lectures and laboratory. In this case, the projects developed in the lab have to be quite small and founded on 


\section{Session T1A}

basic theory. The traditional assessment method for these kind of courses, consists of a midterm and a final exam. The lab mark usually has a small contribution into the final mark.

The OS course in our curriculum is a classical course. However, we have replaced the traditional assessment method with a low cost implementation of continuous assessment.

\section{RELATED WORK}

Several authors use the distinction between summative and formative assessment [2][3][4]:

- Formative assessment: the main objective is learning. Information is used to identify strengths and weaknesses, motivate students to study, create learning activities and give feedback to both students and teachers.

- Summative assessment: the main objective is judgement. Information is used to assign grades and certify mastery.

In formative assessment, promptitude has priority over the accuracy and reliability of the evaluation: providing feedback to the student promptly is considered more important than assigning an accurate mark. On the contrary, in summative assessment, evaluation must be precise and reliable, even if it is not offered to the student with promptitude.

Black and Wiliam [2] comprehensive review of formative assessment emphasizes the extraordinarily large and consistent positive effects that feedback has on learning compared with other aspects of teaching.

Gibbs and Simpson [3] present ten conditions under which assessment supports students' learning. In that work, the authors demonstrate the influence of assessment on the volume, focus and quality of studying and the influence of feedback on learning. They point that, in distant learning, feedback on frequent assignments is the only contact with the tutor, and "(students) can cope without much, or even any, face-to-face teaching, but they cannot cope without regular feedback on assignments".

Biggs [4] emphasizes that "learning takes place through the active behavior of the student: it is what he does that he learns, not what the teacher does".

There are several proposals to increase the tasks students must solve, helping them to distribute their effort and to have a productive learning activity. Examples are Project-Based Learning [5], or continuous assessment. In fact, most of them stress on criteria as "long-life learning" and "learning to learn", that form part of the engineering program outcomes of the ABET [6] and EHEA[1].

Whether or not the outcomes of the course are clearly defined, students work out for themselves what counts - or at least what they think counts - towards passing the course, and direct their efforts accordingly. Then, quantitative assessment on teaching and learning provokes what Biggs names backwash effect: he describes an scenario in which the students' learning is directed by their need to know how to pass the assessment, rather than by the curriculum. Thus, "students in their search for marks fail to see the structures being learned; in counting the trees, they get lost in the wood"
([4], p.233). Also, all the aforementioned authors insist in the idea that students distribute their time unevenly across courses, often focusing on topics associated with assessment and nothing else. Frequently, assignments or tests can help distribute student effort across the course, but sometimes they stress the student, while increasing the teachers' workload.

\section{The Proposal}

\section{Motivation}

We wondered why our students did not keep the subject up to date and found three possible reasons:

- Lack of habit: the students are not used to carry out a continued effort voluntarily. Instead, they do it in front of external stimuli as, for instance, having to take an exam.

- Lack of motivation: the students perceive this subject as one that can be passed with some effort just before the exam. The fact that they quickly forget all the knowledge afterwards has almost no importance: passing the course prevails over learning.

- Competition: our course has a strong competition for student's time with a project course within the same term. That course is highly time-consuming for the students.

Summarizing, the students often decided that it was better to devote their effort during the term to other (very demanding) courses. They dedicated to OS only a final effort, just before the exam, because they perceived it as easy to pass.

We could not ask our colleagues to soften their courses. On the other hand, it is beyond our reach to change the lack of habit at once. However, a global change can instill in our students the habit of studying continuously. Thus, we wanted to motivate our students to keep a continuous attention to OS.

A possibility was increasing the number of gradable exercises (e.g. weekly). However, that would imply a big pressure on the students and a big effort from the teachers. Consequently, we did not choose this method. Instead, and in order to encourage the students to keep the subject up to date, we offer the option of passing the course without taking the final exam via our continuous assessment method. At the same time, it is not mandatory to follow such continuous assessment. Any student can obtain $100 \%$ of his grade from the mark of the final exams.

The regulations of our university state that the final mark (FM) can not be the result of a single evaluation act. For the OS course, we divide the grade into two parts: the theory mark (TM) and the lab mark (LM). The former represents a $70 \%$ of the final grade while the later represents a $30 \%$. We demand a minimum mark of 3.5 for the lab to pass the course. Otherwise, the final mark can not be greater than four (i.e. if $\left.\mathrm{LM}<3.5, \mathrm{FM}=\min \left(\mathrm{TM}^{*} 0.7+\mathrm{LM}^{*} 0.3,4\right)\right)$. This condition is essential to force the students to work in the lab.

\section{Theory Mark}

The theory mark is traditionally obtained from a final theory exam. However, we allow for the option of obtaining it through midterm exams, without taking the final exam.

October 10 - 13, 2007, Milwaukee, WI 


\section{Session T1A}

During the term we carry out three short exams. Each covers all the lessons lectured up to that moment. A term has 15 calendar weeks (13 effective weeks discounting holidays). These midterm exams are usually taken on the sixth, tenth and fifteenth week. The first two last for one hour each. The last one lasts for two hours. The weight of each exam is proportional to its length: the first two exams weight $25 \%$ each, while the third one weights $50 \%$.

Our requirement for a student to pass the continuous assessment is: to pass the three midterm exams (mark greater than or equal to 5) or, if he fails one exam, to get a weighted average greater than or equal to 6 .

Students who pass the course via continuous assessment can keep that mark as the theory mark or, instead, they can decide to take the final exam. If they take the final exam then they lose their continuous assessment mark and their theory mark will be the one obtained from the final exam. A student who fails the continuous assessment gets the mark obtained from his final exam.

\section{Laboratory Mark}

Through the 13 effective weeks in a term the students carry out ten lab sessions. Each has a duration of two hours and can be graded. The first two weeks there are no lab sessions because the topics they cover have not been lectured yet. The last week is reserved for the lab exam.

Each lab session is composed of two parts. First, the student has to prepare for the lab session. Such homework requires about two hours. Second, the student attends the lab session. A collection of problems is distributed at the beginning of the session and the student must solve them individually during the session.

A lab session can have up to 20 students. During the lab session, the teacher talks with all the students, discussing their proposals, asking where they find difficulties and offering a continuous feedback. We design the problems so they can be solved within the two hours if the student does his homework.

A student who is not able to finish the problems in time will quickly notice he is not up to date and needs to catch up. Moreover, he knows that his teacher is also aware of that.

At the end of each session, the students submit their work. However, they are told this is only additional information for the teacher. They know their mark will come mainly from the discussions they have with their teacher during the sessions.

At the end of these ten sessions, we publish a subjective mark for each student. This mark reflects the knowledge, dedication and evolution that the teacher has observed during the sessions. This mark cannot be discussed nor reviewed.

Students who obtain a subjective mark lower than five, or disagree with their mark, can take the lab exam. That exam is held on the last week of the term. The exam consists of several ( 3 to 5) problems that are similar to those proposed during the sessions. The final laboratory mark is the maximum between the subjective mark and the exam mark. This means that if a student agrees with his subjective mark he does not need to attend the lab exam.

\section{$I V$. Soundness of the proposal}

Each time we have explained our proposal to our peers, they have raised some doubts about the soundness of the proposal. Next, we will indicate the most common concerns and our answer.

- "I do not like the idea of removing the final exam. It allows for testing for an overall view of the student's knowledge". True, but our midterm exams test the subject up to that point. That means that the last one, which is carried out at the end of the term, allows for testing for such overall view.

- "The students who fail on the first exam will quit the continuous assessment". False, because it is not mandatory to pass the three exams to pass the assessment if the average mark obtained for the three exams is greater than or equal to 6 . Since the third exam weights $50 \%$ of the mark, they know they can recover and continue the continuous assessment. An exception can be the student who gets a really low mark. However, he has detected that he is not in the right track early during the term (sixth week). Furthermore, the students perceive the exams as good training for the final exam.

- "Students that get good marks in the first two exams will neglect the subject". Quite the opposite, since the possibility to avoid the final exam is a very tempting prospect. The third exam weights $50 \%$. Thus, a student with an average of 7.5 in the first two exams will fail the continuous assessment if he gets a mark of 4 in the last one, because the weighted average of the three exams is less than 6 (that is the motivation behind this restriction).

- "The laboratory subjective mark can be unfair". True, but the mark comes from twenty hours of observation by the teachers. The lab problems are done individually so when students pass the lab it is because they have shown enough knowledge of the subject. It could be unfair with students who are shy or have communication problems. However, those students can always take the lab exam.

- "Continuous assessment should be voluntary". We fully agree: that is why the course can be passed by just taking the laboratory exam and the final theory exam.

- "If all the courses did the same, it would be too much load for the student". On the contrary: if all courses used our method, the student would distribute his time much better. In fact, we demand 150 hours of work by the student (including lecturing, labs, etc.) along 15 weeks for a 9 credit course; on average a student has 37.5 credits per term. If all courses did the same, the student would have to devote 41.6 weekly hours to his studies, which is perfectly reasonable.

- "The cost of implementing this method must be very large for the teachers". We discuss this issue in the next section.

\section{Costs of The Proposal}

We have already commented that one of the complaints against the implementation of continuous assessment is the 


\section{Session T1A}

high cost for both the teacher and the student. So, which are the costs of our proposal?

\section{Costs for the teacher: assessment of the theoretical part}

We compare a method with one midterm exam plus a mandatory final exam against a method with three midterm exams and a make-up final examination. In our continuous assessment method, students who pass the midterm exams do not have to take the final examination. However, in case they take it, their mark will be the one obtained from the final exam. Most students do not take the risk to fail a course if they have already passed it. Only students who are confident to improve their marks hand in the final exam. In five terms only three students in this situation did so. All of them improved their marks.

With regard to the preparation of the exams, the instructor has to write a final examination in both cases. However, in our implementation of continuous assessment, three midterm tests have to be elaborated whereas with the conventional evaluation method only one midterm test is necessary. In this case there is an increase in the cost associated to our proposal.

As for the correction, let's assume that the examinations are similar in both types of evaluation. Then, we consider that the effort of marking is proportional to the duration of the exam. If a student has to take a two-hour midterm exam plus a three-hour final exam, then the teacher must correct the effort of five hours of examination on the part of the student. If a student takes two one-hour and one two-hour midterm exams and manages to avoid the final exam, then the teacher must correct the effort of a total of four hours of examination.

In the last term (fall 2006) 143 students enrolled for our course. 131 handed in the first exam, 122 handed in the second and 102 the third. Finally, 47 students handed in the final exam. Therefore, we had to correct the result of $131 \times 1 \mathrm{~h}$ $+122 \times 1 h+102 \times 2 h+47 \times 3 h=598$ hours of examination.

In order to compare our method with the traditional method, let's suppose that all the students who have handed in the first exam with our current assessment method would have also done so in the midterm exam in a traditional method: we would have 131 two-hour midterm exams to mark. The last term before the method was changed, $89 \%$ of the students handed in the final exam. Then, assuming $89 \%$ of the 143 students handed in the final examination, we would have 127 three-hour exams to mark. This would result in $131 \times 2 \mathrm{~h}+$ $127 \times 3 \mathrm{~h}=643$ hours of exam to be marked.

This difference does not necessarily indicate that the cost of the new method is smaller than the cost of the traditional one. However, we believe it shows that our implementation of continuous assessment does not have a larger cost. In addition, the correction is distributed throughout the term.

\section{Costs for the teacher: assessment of the laboratories}

The main cost in relation to the labs comes from the elaboration of a handbook for the laboratory. It consists of documentation the students should read before attending the labs and a list of exercises. This handbook is prepared once, when the course is first designed, and reused across different terms, with only some occasional updates. Therefore, we can consider this work as part of the course design. Once we have the handbook, the teacher's work will mainly consist in:

- Developing proposals for assignments for every group and session: one or a few short assignments which are usually based on exercises found in the collection within the handbook. They can be used later to update the handbook. The time needed to elaborate each assignment is quite small. In any case, we must take into account that in traditional systems assignment proposals have to be elaborated anyway.

- Supervising the students' work. This supervision is carried out during the laboratory hours: thanks to the teacherstudent conversations the student gets immediate feedback while the teacher obtains information about the student's progress. Based on these conversations the teacher assigns a subjective mark to each student. The great advantage lies in the fact that both feedback and marking are done within the laboratory sessions.

- Prepare and mark the laboratory exam. However, few students show up at the final make-up laboratory exam (about 10\%) since most of them have already passed the labs (subjective mark) or have already abandoned the course. Thus, a very short time is needed to mark those exams.

It is difficult to compare our lab with those in other courses since there are many ways of implementing a laboratory. However, our proposal overlaps the sessions of laboratory with their evaluation. Consequently, the cost or their assessment is rather small.

\section{Costs for the student: ECTS credits}

The European Credit Transfer System (ECTS) [7] is a unit of appraisal of the academic activity of the student. It takes into account the assistance of the student to lectures, the time of personal study, exercises, labs, and assignments, together with the time needed to undertake examinations.

A term has an average of thirteen weeks. Each week the students in our course have four hours of theoretical lectures. They are supposed to invest about four extra hours of personal study per week. Labs last for two hours. The students should invest another two hours to prepare each lab. There are ten laboratory sessions. Midterm exams are done during some of the theoretical lectures. Thus, a student who passes the course via continuous assessment invests about 144 hours.

If a student needs to take the exams, then up to five hours should be added: two hours for the laboratory make-up exam and three hours for the final theory exam. Let's assume students invest six hours to review the subject in preparation for the exams. This amounts to eleven additional hours. Consequently, a student invests between 144 and 155 hours to pass our course.

The important thing is that we specify the work, and the corresponding number of hours, students should dedicate to our Operating Systems course. We provide this information independently of whether they follow the continuous 


\section{Session T1A}

assessment method or not. The continuous assessment should be useful to help students distribute their work throughout the term.

\section{Evaluation of The Proposal}

In order to evaluate our proposal, we will consider five main points: follow-up and results of the continuous assessment; dedication of the student to the course; comparison with a more traditional methodology; students' opinion with respect to the assessment methodology; and teachers' evaluation.

\section{Follow-up and results of the continuous assessment}

The number of students that enroll for the course ranges from 130 to 170 . Due to space constrains we will only show results from the last term. Results from previous terms are similar.

As we stated above, last term (fall 2006) there were a total of 143 students attending the course. During that term, about $70 \%$ of the students followed the continuous assessment for the theoretical part of the course, i.e. they have taken all the midterm examinations. In addition, $15 \%$ of the students started the continuous assessment but withdrew from it (mainly due to the low marks they obtained for the first two midterm exams). Thus, a total of $85 \%$ of the students have tried to follow the continuous assessment.

From the $70 \%$ of the students that completely followed the continuous assessment, about $78 \%$ successfully passed the theoretical part without taking the final examination $(54.6 \%$ from the total number of students). Notice that the midterm exams and the final examination have the same level of difficulty. Consequently, the minimal requirements to pass the course are the same.

With respect to the practical part of the course, about $95 \%$ of the students followed the continuous assessment. The fact that the teacher supervises the student's learning through every class providing immediate feedback proves useful since nearly $89 \%$ of the students successfully pass the labs. Less than $2 \%$ of the students decided to improve their marks taking the final examination.

Summarizing, most of the students followed the continuous assessment with a high success ratio.

\section{Dedication of the student to the course}

A student has to distribute his hours of homework among several courses during the same term. For this reason, following a continuous assessment should not take more hours of homework than those assigned according to the ECTS. Furthermore, those hours should not be concentrated just before the midterm or final examinations.

Our school promotes a project (named ECTS project) meant to collect the student's dedication to each course per week. Data is divided into theory, labs and actual study. Figure 1 shows the average amount of hours per week that students dedicate to study each course in the same level as OS. Data corresponds to the spring 2006 term, with a sample size of $14 \%$ from the total amount of students.

Students taking OS usually take four other courses within the same term: Software Engineering I (SE1), Analysis and
Design of Algorithms (ADA), Programming Project (PROP) and Databases (DB). Each of them uses a different assessment methodology.

Two important points can be drawn from Figure 1. The first point is that the number of hours of homework needed to follow the continuous assessment in OS is similar to that of the other "classical courses" (which use a rather traditional assessment methodology). However, PROP is a "project course" in which the students dedicate an extraordinary amount of hours to develop a mid-size project. In fact, this course presents a problem to the teachers of the others courses in the same level. Since the number of hours of homework per week is bounded, a student that wants to pass PROP has to dedicate less time to the others courses. This could lead to an extreme and undesirable situation in which the students had to withdraw other courses because they did not have enough time to study them. Thus, it is very important that the student can follow the continuous assessment at a reasonable cost.

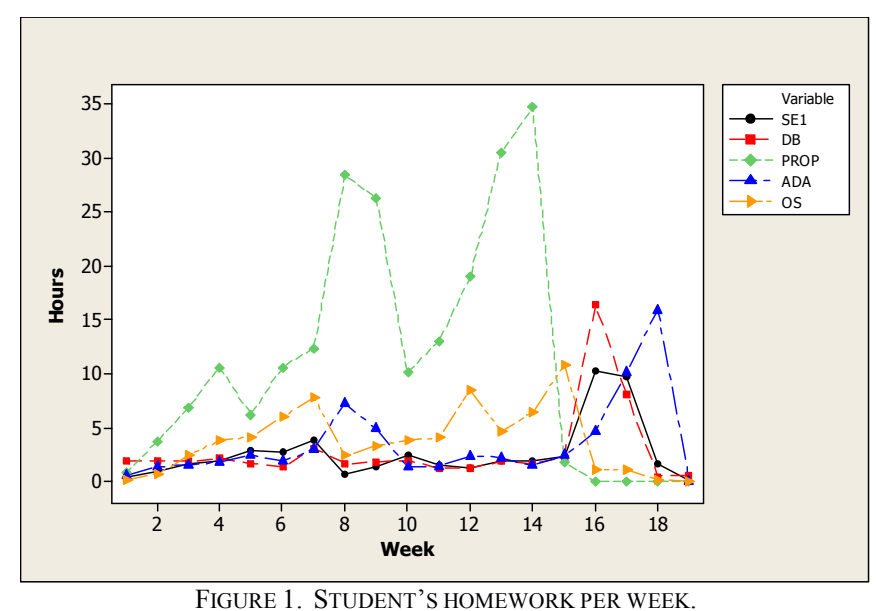

The second point which can be seen in Figure 1 is that, due to our continuous assessment methodology, students dedicate several hours of homework every week to our course. In other classical courses, however, students concentrate their study during the final exams (weeks 16 to 19). We believe that working regularly, on a week basis, on the new concepts learned during the lectures and labs can result in a more successful learning process.

\section{Comparison of the results with a traditional methodology}

The Operating System (OS) course is an extension of the Introduction to Operating Systems (IOS) course we had before year 2004 in the former curriculum. OS was created with the evaluation methodology explained in this paper. IOS, however, used the traditional evaluation methodology consisting in one midterm exam (optional and used to improve the final mark) and a final exam. In addition, students had to take a final lab exam to pass the practical part of the course.

Figure 2 shows the final marks of IOS from fall 1997 to spring 2004 (last term) and OS from that point onwards. Marks shown are divided into quartiles (asterisks correspond to outliers). We believe the comparison is fair since the

October 10 - 13, 2007, Milwaukee, WI 


\section{Session T1A}

minimal requirements to pass the course are similar for both OS and IOS. Actually, OS could be regarded as more difficult to pass than IOS since it covers more concepts.

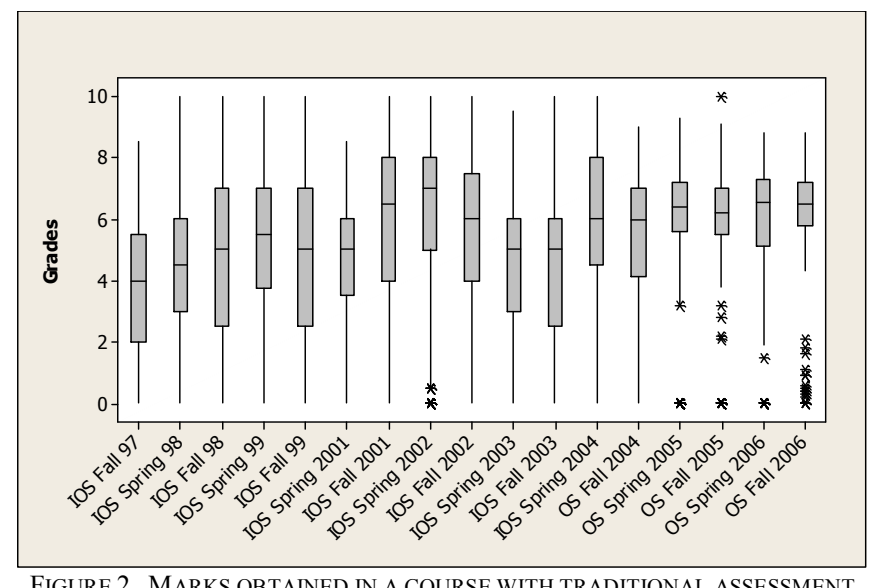

FIGURE 2. MARKS OBTAINED IN A COURSE WITH TRADITIONAL ASSESSMENT (IOS) AND A COURSE WITH OUR CONTINUOUS ASSESSMENT PROPOSAL (OS)

There are two important details to remark about Figure 2. First of all, the average mark of OS is, in general, the same or even better than that of IOS. We believe OS students use their time more profitably thanks to the continuous assessment methodology and their knowledge is better consolidated.

The second detail relates to the dispersion of marks. In IOS this dispersion is wider than is OS. Since in OS, the final mark depends on more examinations, there are less extreme values. In IOS, the final mark depended directly on the final examination, whereas the midterm exam and the practical examination were only used to perform a slight modulation of that mark. Since the final mark depended mainly on a unique examination, it was more likely for a student to obtain extreme marks. Therefore, the continuous assessment prevents the student from being either harmed or benefited by non academic factors.

These two characteristics make us think that the assessment methodology presented helps students use their time profitably and allows for a fair evaluation.

\section{$I V$. Students' surveys}

We have surveyed the students to know their opinion about the continuous assessment methodology. In the survey we asked about the students agreement with respect to seven assertions dealing with the course and its assessment. The answers range from one (desagree completely) to four (agree completely). One of these assertions was "I think the continuous assessment helps me to follow the course". For this one, $91 \%$ of the students surveyed agreed completely. Another important assertion was "I think the continuous assessment will help me pass the course". In that case, $89 \%$ of the students also agreed completely.

We believe that those figures point out the fact that the methodology is useful from the students' point of view.

\section{Teachers' evaluation}

An indication of the failure or success of our proposal may be the personal appreciation of the teachers. We have the feeling that lectures are now more useful and students are able to understand the new concepts built on previous lectures. Unfortunately, such an opinion is hard to justify and can easily lead to self-deception. In this case, however, we believe we can consider our proposal successful since we have provided enough indicators throughout the paper.

\section{CONCLUSIONS}

We have presented the continuous assessment methodology that we use in our OS course. The basis of this methodology consists in the separation of formative and summative assessment. The practical implementation of the methodology has a reasonable cost for both students and teachers.

The fact that the final exam is not mandatory motivates the students to follow the continuous assessment obtaining good results with a reasonable amount of homework hours.

Students feel confident with the continuous assessment methodology since they perceive that it helps them passing the course. Teachers believe students take more advantage of lectures and labs.

\section{ACKNOWLEDGMENTS}

We wish to thank the Barcelona School of Informatics for providing us with the ECTS project results. This work has been supported by the Spanish Ministry of Education and Science (project TIN2004-07739-C02-01).

\section{REFERENCES}

[1] Confederation of EU Rectors' Conference. "The Bologna Declaration on the European space for higher education: an explanation". [On line http://ec.europa.eu/education/policies/educ/bologna/bologna.pdf; access data: February , 20 2007]

[2] Black, P.; Wiliam, D. "Assessment and Classroom Learning", Assessment in Education, vol. 5, no. 1, pp.7-74, 1998.

[3] Gibbs, G.; Simpson C. "Conditions Under Which Assessment Supports Student's Learning". Learning and Teaching in Higher Education, Issue 1, pp.3-31, 2004-2005.

[4] Biggs, J. "The reflective institution: Assuring and enhancing the quality of teaching and learning". Higher Education vol.41, no 3, pp. 221-238, 2001.

[5] Buck Institute for Education. "Project Based Learning" [On line http://www.bie.org/pbl; accessed: January, 12 2007].

[6] Engineering Accreditation Commission. "Criteria for Accrediting Engineering Programs". Accreditation Board for Engineering and Technology (ABET), Baltimore, Maryland, USA, 2004.

[7] European Commission. "European Credit Transfer and Accumulation System". [On line http:/ec.europa.eu./education/programmes/socrates/ ects/index_en.html; accessed January, 15 2007]. 